\title{
Environmental hepatitis E virus detection supported by serological evidence in the northwest of Argentina
}

\author{
María B. Pisano ${ }^{a, b, *}$, Belén C. Lugo ${ }^{a}$, Ramiro Poma ${ }^{c}$, Héctor A. Cristóbal ${ }^{c}$, Viviana Raskovsky ${ }^{d}$, \\ Maribel G. Martínez Wassaf ${ }^{b, e}$, Verónica B. Rajal ${ }^{c, f}$ and Viviana E. Réa,b
}

\begin{abstract}
${ }^{a}$ Instituto de Virología 'Dr. J. M. Vanella', Facultad de Ciencias Médicas, Universidad Nacional de Córdoba, CONICET, Enfermera Gordillo

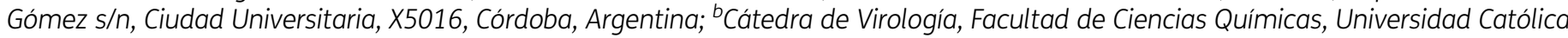
de Córdoba. Av. Armada Argentina 3555, X5016DHK, Córdoba, Argentina; ${ }^{C}$ Instituto de Investigaciones para la Industria Química (INIQUI) -CONICET, Universidad Nacional de Salta, Av. Bolivia 5150, CP: 4400, Salta, Argentina; ${ }^{d}$ Hospital Señor del Milagro, Av. Sarmiento 557, CP: 4400, Salta, Argentina; 'Laboratorio de Virología y biología molecular, LACE, Av. Vélez Sársfield 528, X5000JJS, Córdoba, Argentina; f́Facultad de Ingeniería, Universidad Nacional de Salta, Av. Bernardo Houssay 1099, CP: 4400, Salta, Argentina
\end{abstract}

*Corresponding author: Tel: +54 351 4334022; E-mail: mbelenpisano@gmail.com.

Received 9 January 2018; revised 28 February 2018; editorial decision 2 May 2018; accepted 2 May 2018

Background: Hepatitis E virus (HEV) is an emergent cause of acute hepatitis worldwide. Water contamination is a possible source of viral infection. In South America, particularly in Argentina, little is known about environmental HEV circulation, including recreational water. The aim of this work was to provide evidence of current environmental and human circulation of HEV in northern Argentina.

Methods: Molecular detection of HEV in water samples from the Arias-Arenales River in the city of Salta by nested polymerase chain reaction (ORF2 region) and anti-HEV immunoglobulin G (IgG) and IgM detection in the general population by enzyme-linked immunosorbent assay was carried out.

Results: HEV RNA was detected in 1.6\% (3/189) of the environmental samples. All sequences belonged to HEV genotype 3 and were very similar to those previously detected in the country. The prevalence of IgG anti-HEV was $9 \%$ (13/143) and three samples were positive for specific IgM.

Conclusions: Circulation of HEV in the northwest of Argentina was demonstrated for the first time, showing viral presence in environmental samples and infections in people who attended health care centres for routine control. These findings show that recreational waters are a possible source of virus and highlight the need to carry out HEV detection when a case of hepatitis occurs.

Keywords: Argentina, environmental detection, HEV, molecular epidemiology, seroprevalence, watercourse

\section{Introduction}

Hepatitis E virus (HEV) is an important pathogen with a worldwide distribution. It is a spherical, non-enveloped virus (family Hepeviridae, genus Orthohepevirus, species Orthohepevirus A) with a single-stranded positive-sense RNA genome approximately $7.2 \mathrm{~kb}$ in length. ${ }^{1} \mathrm{HEV}$ is the causative agent of endemic and epidemic hepatitis in developing countries ${ }^{2,3}$ and it is increasingly recognized as a significant cause of hepatitis in the developed world. ${ }^{4}$

Many HEV genotypes have been described. Genotypes 1, 2, 3, 4 and 7 infect humans, ${ }^{5}$ although all belong to a single serotype. ${ }^{6}$ Genotypes 1 (HEV-1) and 2 (HEV-2) are responsible for large epidemics in endemic regions of Asia, north Africa and
Mexico (HEV-2). Humans are the only described hosts for these genotypes and transmission usually occurs by the faecal-oral route via contaminated drinking water or by human-to-human contact. ${ }^{6,7}$ Genotypes 3 (HEV-3) and 4 (HEV-4) are zoonotic and are transmitted by direct contact with infected animals or via consumption of raw or undercooked animal meat. These genotypes cause autochthonous sporadic cases in developed and non-endemic regions, such as the United States and Europe. ${ }^{7}$ Exposure to contaminated water is postulated to have an important role in the transmission of these subtypes, especially in cases where a direct zoonotic exposure does not occur. Some studies have reported that sewage disposal from pig slaughterhouses and/or untreated urban sewage poses a risk to environmental contamination of watersheds (rivers, dams) ${ }^{8-10}$ as well

(c) The Author(s) 2018. Published by Oxford University Press on behalf of Royal Society of Tropical Medicine and Hygiene. All rights reserved. For permissions, please e-mail: journals.permissions@oup.com. 
as the water distribution network, causing waterborne infections in the exposed population. ${ }^{11}$ There is a considerable lack of understanding of the transmission and life cycle of HEV, ${ }^{12}$ especially in low-income countries such as those of South and Central America, where few studies on HEV in recreational water have been performed. ${ }^{10,13,14}$

Sporadic human cases of acute hepatitis due to HEV-3 have been reported in many parts of Argentina; ${ }^{15}$ however, the diagnosis of hepatitis $E$ is not yet routine. In the northern provinces, two cases of acute hepatitis $E$ have been recorded. In the first case, a 1-year-old boy with hepatitis A virus co-infection experienced fulminant hepatic failure. ${ }^{15}$ The second case was a 26-year-old woman with human immunodeficiency virus (HIV) co-infection. ${ }^{16}$

Our group showed, for the first time in South America, the presence of HEV-3 (subtype 3c) in an environmental water source (river) and in sewage in the central area of Argentina, ${ }^{10}$ demonstrating that waterborne infections could occur in the region. However, there are no studies carried out in other parts of Argentina (including Salta, a province in the northwest region that borders Bolivia, Chile and Paraguay) and studies in the rest of South America are scarce. Additionally, no serological studies have been performed in the northern region of Argentina, demonstrating the lack of information regarding local HEV prevalence.

Several questions arise then with regards to HEV circulation in this region of Argentina. The circulation and proportions of HEV genotypes/subtypes in the area, the similarity to those of bordering countries such as Bolivia (the large informal trade between countries in that area provides a means for infected humans who cross the border to spread the virus), the HEV prevalence in the general population and any environmental reservoirs (such as contaminated watersheds) of the virus in the region remain unknown.

In the current study we aimed to investigate HEV circulation in the city of Salta, by molecular detection in water samples from the Arias-Arenales River and serological screening of people who attended health care centres for routine control.

\section{Materials and methods}

\section{Environmental samples}

Water samples were collected from the Arias-Arenales River, located in the province of Salta, in the northwest area of Argentina (Figure 1A), $746 \mathrm{~km}$ from the province of Córdoba (where HEV was detected in humans, river water and sewage) and $1281 \mathrm{~km}$ from the province of Buenos Aires (where acute cases of HEV have been reported). The Arias-Arenales River belongs to the Juramento-Salado watershed in Salta and it is subjected to seasonal fluctuations in water flow during the rainy and drought seasons present in summer and winter, respectively. The river runs west to east through a semirural area where the main use is for water supply, agricultural irrigation, recreational activities and livestock maintenance. When the river crosses the city, it receives pollution, such as illegal raw sewage, domestic and industrial effluents, illegal solids (deposits of domestic waste on the river banks) and many other untreated pollutants. ${ }^{17}$ Eleven collection points (P1-P11) were used along the river where it runs through the city of Salta $(12.5 \mathrm{~km})$ during
2009-2010 $(n=117)$ and 2013-2014 $(n=72)$ (Figure 1B). Briefly, P1 and P2 were selected as low pollution controls on the Arias and Arenales Rivers, respectively, before entering the city; P3, P7, P8 and P9 are stormwater sources flowing into the river; P4 is on the Isasmendi Creek at the confluence with the Arias River, where a beef packing plant is located; P5 receives untreated sewage; P6 corresponds to a recreational area called Parque Los Sauces (with picnic tables, grills and a place for children to play); P10 and P11 are upstream and downstream of the wastewater treatment plant and municipal landfill. A reduction of water quality has been registered between P10 and P11, due to the wastewater treatment plant, which periodically discharges raw sewage directly into the river due to operational failure or treatment undercapacity. ${ }^{17}$ One sample was collected per sampling point the first week of each month, during the morning. In months of low rainfall, some points were not monitored due to lack of flow.

For each sample, $20 \mathrm{~L}$ of water was collected in clean plastic containers. Samples were then concentrated by ultrafiltration (concentration factor was approximately 400x). The water samples were filtered through stainless steel sieves to remove solids, placed into the feed tank and pumped through an ultrafiltration system using a peristaltic pump. Two membrane units were used: Microza AHP 1010 (Pall Life Sciences, Port Washington, NY, USA) and Polyflux 24R (Gambro, Deerfield, IL, USA) for the different monitoring periods. Two separate elution steps using $20 \mathrm{~mL}$ (for each one) of a solution containing $0.05 \mathrm{M}$ glycine/sodium hydroxide $(\mathrm{pH} 7.0)$ and $0.1 \%$ Tween 80 were performed. The final concentrated sample $(50 \mathrm{~mL})$ consisted of the eluate from the ultrafiltration unit plus the final retentate. ${ }^{17}$ The bacteriophage PP7 was added to the water samples as an internal control to test for inhibitors, as previously described. ${ }^{17}$ According to Poma et al., the recovery of PP7 from environmental samples using the ultrafiltration method was between $1.5 \%$ and $29.7 \%$. ${ }^{17,18}$

\section{Extraction of RNA}

Viral nucleic acids were extracted from $140 \mu \mathrm{L}$ of concentrated riverine samples using the QIAamp Viral RNA Kit (Qiagen, Hilden, Germany), following the manufacturer's instructions. In brief, each sample was subjected to lysis, centrifugation, passage through the column, washing and elution in a final volume of $60 \mu \mathrm{L}$.

\section{Molecular detection of HEV and sequencing of positive samples}

For complementary DNA (CDNA) synthesis, $10 \mu \mathrm{L}$ of the extracted RNA was incubated at $65^{\circ} \mathrm{C}$ for $10 \mathrm{~min}$, then $10 \mu \mathrm{L}$ of a mixture containing $1 \mu \mathrm{L}$ of reverse transcriptase (ImProm-II Reverse Transcriptase, Promega, Fitchburg, WI, USA), $0.5 \mu \mathrm{L}$ of RNAse Out (RNase Out Recombinant Ribonuclease Inhibitor, $40 \mathrm{U} / \mu \mathrm{L}$; Invitrogen, Waltham, MA, USA), $4 \mu \mathrm{L}$ of buffer $5 \times$ (ImProm-II Reverse Transcriptase, Promega), $2.4 \mu \mathrm{L}$ of $25 \mathrm{mM} \mathrm{MgCl}_{2}, 10 \mathrm{pmol}$ of random hexamer primers (Promega), $1 \mu \mathrm{L}$ of $10 \mathrm{mM}$ nucleotides (dNTPS) and $0.1 \mu \mathrm{L}$ of RNAse-free water was added. The sample 


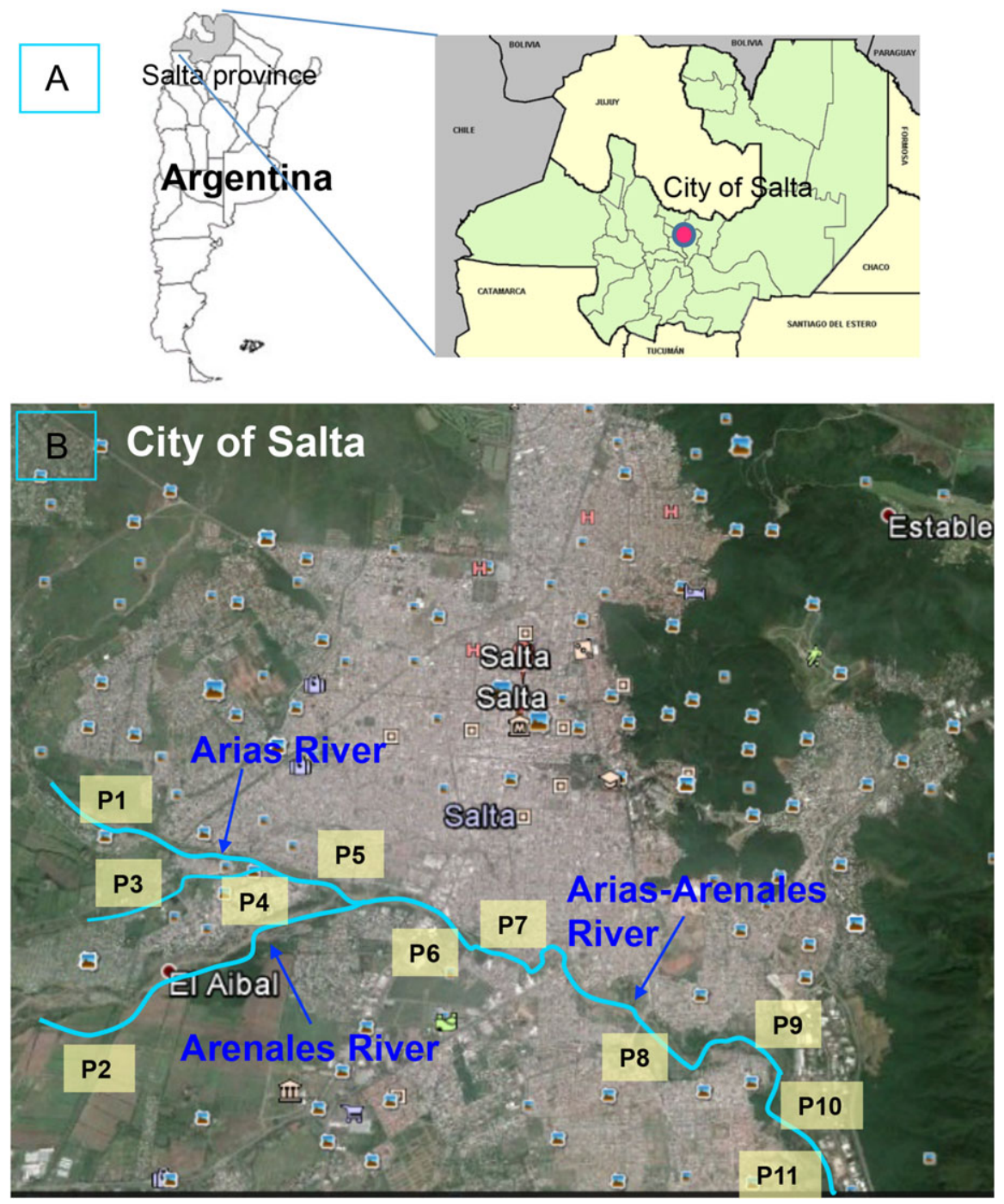

Figure 1. Site of study. (A) Location of Salta province and its capital city (city of Salta). (B) City of Salta and the Arias-Arenales river with the 11 sampling points (P1-P11): P1 and P2 were selected as low-pollution controls in the rivers Arias and Arenales, respectively, before their entrance into the city. P3, P7, P8 and P9 are stormwater sources flowing into the river. P4 is in the Isasmendi Creek. P5 is a point of discharge of untreated sewage. P6 is a point located in a recreational area called Parque Los Sauces. P10 and P11 are located upstream and downstream of the wastewater treatment plant (WWTP) and municipal landfill. ${ }^{17}$

was then incubated at $42^{\circ} \mathrm{C}$ for $1 \mathrm{~h}$, followed by a final incubation at $68^{\circ} \mathrm{C}$ for $10 \mathrm{~min}$.

Genomic detection of HEV was performed with a nested polymerase chain reaction (PCR) protocol amplifying a 348-bp fragment of the ORF2 region for HEV 1-4 genotypes using primers $5^{\prime}$ AAYTATGCMCAGTACCGGGTTG-3' (S) and 5'-CCCTTATCCTGCTGAGC ATTCTC-3' (AS) for the first round of PCR and 5'-GTYATGYTYTGC ATACATGGCT-3' (S) and 5'-AGCCGACGAAATYAATTCTGTC-3' (AS) for the second round. ${ }^{19} \mathrm{CDNA}(5 \mu \mathrm{L})$ and $2 \mu \mathrm{L}$ of PCR product were used in the first and second PCR, respectively, and added to a mixture containing $10 \mu \mathrm{L}$ of GoTaq buffer $5 \times$ (Promega), $1 \mu \mathrm{L}$ of $10 \mathrm{mM}$ dNTPs, $0.25 \mu \mathrm{L}$ of DNA polymerase GoTaq (Promega), 20 pmol of each primer and RNase-free sterile water to make a final volume of $50 \mu \mathrm{L}$. The cycling conditions were initial denaturation at $94^{\circ} \mathrm{C}$ for 5 min followed by 40 cycles (first PCR) or 30 cycles (second PCR) of $94^{\circ} \mathrm{C}$ for $1 \mathrm{~min}, 45^{\circ} \mathrm{C}$ for $1 \mathrm{~min}$ and $72^{\circ} \mathrm{C}$ for $1 \mathrm{~min}$ with a final extension at $72^{\circ} \mathrm{C}$ for $7 \mathrm{~min}$. The amplicons were analysed by electrophoresis using a $2 \%$ agarose gel stained with Gel Red (Biotium, Fremont, CA, USA) and visualized under ultraviolet light.

With the aim to determine the limit of detection (LOD) of the nested PCR, 10-fold dilutions $\left(10^{-1}-10^{-12}\right)$ of an HEV genotype 1 RNA transcript containing the entire ORF2 region were used. Quantitation of the RNA transcript was performed using a Qubit Fluorometer (Invitrogen) and the number of viral genomes was determined with the following formula: RNA concentration ( $\mathrm{g} / \mu \mathrm{L}) \times$ Avogadro's number/ fragment length (number of nucleotides) $\times 340$. The LOD obtained for the nested PCR was $10^{4}$ viral genome copies (dilution $10^{-9}$ of the transcript).

The PCR products were submitted to Macrogen (Seoul, Korea) for direct sequencing in both directions. The sequences were deposited in GenBank (accession numbers KX812463 and KY511413). 
Table 1. HEV-positive samples obtained from the Arias-Arenales River (Salta province, Argentina)

\begin{tabular}{lllll} 
Sample ID & Date of collection & Point of collection & Sequenced ORF2 & Accession number \\
\hline AmbRSalta_Jun8 & June 2009 & P8 & No* & - \\
AmbRSalta_Ago7 & August 2009 & P7 & Yes & KX812463 \\
AmbRSalta_May10 & May 2013 & P10 & Yes & KY511413
\end{tabular}

*The sequencing result of this sample was not of good quality, therefore it could not be used in the analysis.

\section{Phylogenetic analysis}

Phylogenetic analysis was carried out utilizing MEGA software version $6,{ }^{20}$ using the $p$-distance model and the neighbour joining method. Bootstrap values were determined with 1000 resamplings of the dataset. Reference sequences for each genotype were included, ${ }^{5}$ as well as all other Argentinean sequences available in GenBank.

\section{Serum samples}

A retrospective, non-associated, anonymous study was carried out using 143 randomly selected serum samples (52 male, 91 female; mean age 36 y [range 4-91]) collected from people who attended health care centres near the Arias-Arenales River for routine control between January 2015 and July 2016. Since these samples belonged to a serum bank, they were stored at $-20^{\circ} \mathrm{C}$. The samples were processed in accordance with the requirements of the Ministry of Health of Salta Province and complied with the ethical standards of the Helsinki Declaration (1964, amended most recently in 2008) of the World Medical Association.

\section{Serological tests}

Serum samples were analysed for immunoglobulin $G$ (IgG) and IgM anti-HEV antibodies using a third-generation enzyme immunoassay (EIA; Diapro, Milan, Italy), following the manufacturer's instructions. Test results were interpreted as the ratio of the sample and the cut-off. Samples with a ratio $<0.9$ were considered negative, samples with a ratio between 0.9 and 1.1 were considered equivocal and samples with a ratio $>1.1$ were considered positive.

\section{Statistical analysis}

Prevalence values were expressed as percentages. To assess the association between individual variables (sex, age) and IgG antiHEV, we used independent t or $\chi^{2}$ tests. Exact 95\% confidence intervals (CIs) were utilized. Statistical significance was defined at $p<0.05$. The statistical program InfoStat version 2016 (InfoStat Group, National University of Córdoba, Córdoba, Argentina; http://www.infostat.com.ar) ${ }^{21}$ was used for all statistical analyses.

\section{Results}

Of the 189 water samples tested, three were positive for HEV RNA (1.6\%) (Table 1). Two of these were obtained at lowpollution sampling points (P7 and P8) during 2009 and one at a high-pollution point (P10) during 2013. These positive samples were collected during the cold months (the mean temperature from March to September in Argentina is $\left.14.5^{\circ} \mathrm{C}\right)^{22}$ and dry season (the mean rainfall in fall and winter in Argentina is $38.3 \mathrm{~mm}$ and $4.2 \mathrm{~mm}$, respectively) ${ }^{22}$ (Table 1 ). Phylogenetic analyses showed that these samples belonged to HEV genotype 3 (clade abchij), together with environmental (sewage and river water) sequences previously reported from Córdoba, Argentina (Figure 2).

The positivity rate for IgG anti-HEV antibodies in human sera was 9\% (13/143). There were no statistically significant differences in anti-HEV antibody prevalence by gender (women $7.6 \%$, men $11.5 \%$; $p>0.05$ ) or age ( $p>0.05)$, although a trend of increasing prevalence with age was observed $(25 \%$ in adults $>46 \mathrm{y}$ of age, $7.4 \%$ in adults $31-45 \mathrm{y}$ of age and $2.4 \%$ in young adults [<30 y of age] and children). Of the 13 IgG-positive samples, three were positive for anti-HEV IgM antibodies, indicating recent infections. Liver enzymes of these patients were normal or slightly elevated (alanine transaminase 35-82 U/L, aspartate transaminase 23-42 U/L) and no signs or symptoms were recorded that indicated asymptomatic infections.

\section{Discussion}

In non-endemic countries, HEV-3 has been proposed to be transmitted to humans in a zoonotic fashion from animal reservoirs, mainly through the ingestion of contaminated meat. ${ }^{23}$ Water sources have also been postulated to be implicated in HEV transmission, since several studies have detected HEV in environmental water sources. ${ }^{10,11,24}$

In this study we detected HEV-3 for the first time in a watershed in the province of Salta in the northwest of Argentina and described a positivity rate of IgG anti-HEV antibodies of $9 \%$ in humans, demonstrating the circulation of this virus in the city.

Molecular analysis of water from the Arias-Arenales River showed diffuse HEV contamination, without the presence of a punctual viral source. Positive samples were collected at sites where no specific source of contamination was recorded. There are no farms or slaughterhouses near the sampling points of the study, since it is an urban area. However, numerous garbage dumps and small sewage effluent discharges from illegal urban 


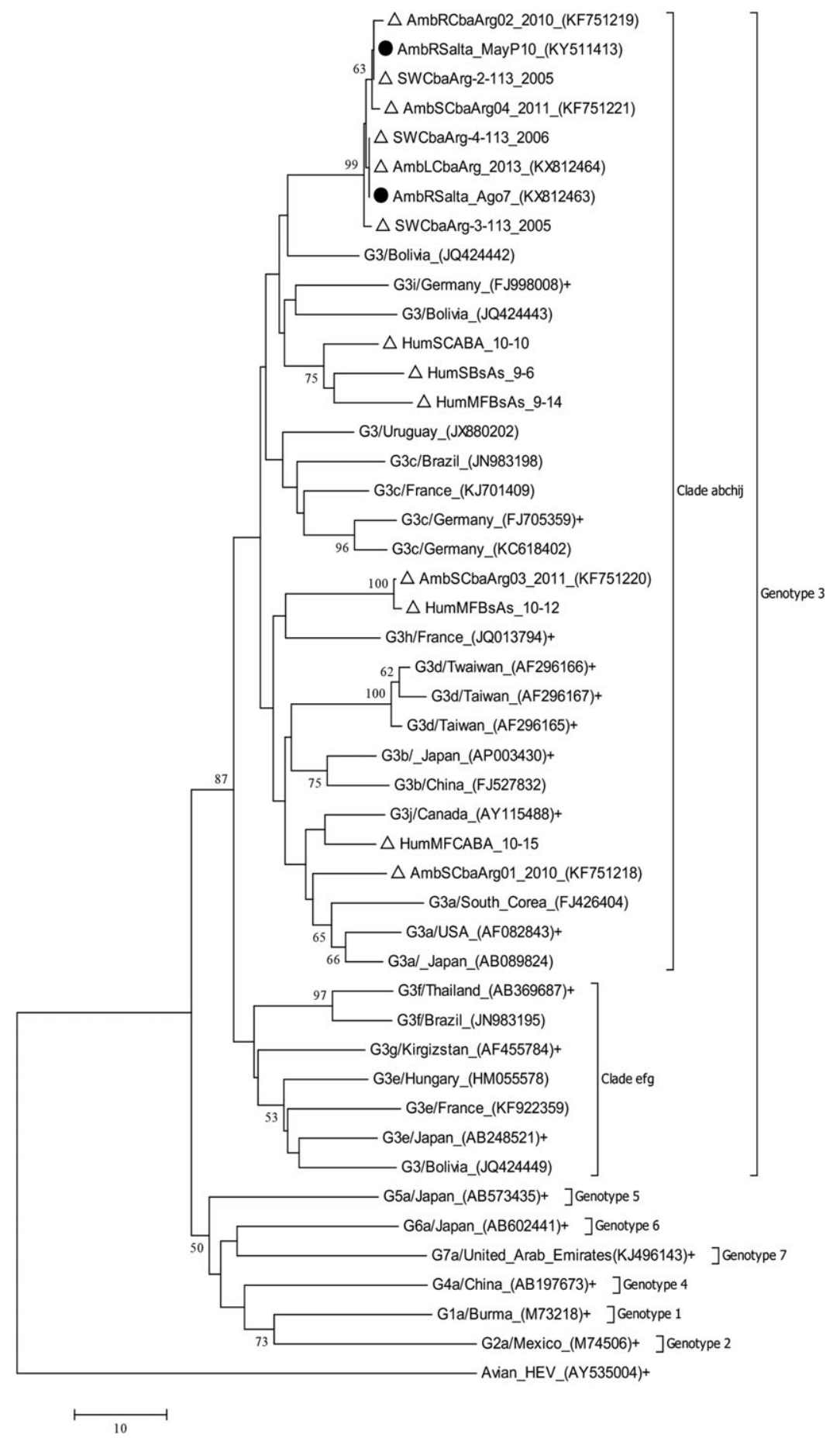

Figure 2. Phylogenetic tree showing environmental HEV strains detected in Salta, Argentina. The dendrogram was constructed using the neighbour joining method (p-distance) with HEV ORF2 236-bp sequences (Mega 6 software). ${ }^{20}$ Each sequence is identified by the genotype (G), country and GenBank accession number. An avian HEV was included as an outgroup. AmbRSalta are sequences detected in the Arias-Arenales river during this work (black circles). Proposed reference sequences for each subtype were included and indicated with.$+^{5}$ Sequences labelled with a triangle belong to Argentinean strains; some of these are from environmental samples from Córdoba (sewage and river), previously reported. ${ }^{10}$

settlements were identified on the sides of the river, ${ }^{17}$ which could be the viral source in the samples collected at these lowpollution sampling points.
Studies from other non-endemic countries have evaluated the sources of HEV infections. Heldt et al. $^{13}$ performed HEV detection in water and sediment samples from a Brazilian river 


\section{B. Pisano et al.}

and in pork products from the same area. Only food samples were positive, suggesting that contaminated pork products may be the source of HEV infection within that region. ${ }^{13}$ On the other hand, environmental water sources have been identified as a possible reservoir for $\mathrm{HEV}$, like in the case of a tap watermediated HEV outbreak in China, which was most likely caused by contamination of the water network and not by food containing the virus. ${ }^{11}$ In our study, the presence of HEV in river samples could indicate an opportunistic scenario for waterborne infections. Sampling point P6 was a recreational place where picnic facilities have been installed for families to enjoy a day outdoors, and since the river appears to be a viral reservoir, ${ }^{17}$ children, which most likely enter in direct contact with this water, are exposed to the risk of different infectious agents such as HEV. Irrigation of small private gardens in areas bordering the river could also be another source of HEV transmission, since the vegetables that are grown and consumed may be contaminated with HEV present in the river water used for irrigation. A surveillance study investigating self-production and the presence of HEV in vegetables grown in the area would be necessary to elucidate this hypothesis. Limitations of our study are that we did not directly detect the presence of infectious virus, as $\mathrm{HEV}$ is very difficult to isolate in cell culture. However, having found HEV RNA in recreational water provides evidence that the entire viral particle was present at one point in time. Also, the low LOD determined for the nested PCR could lead to falsenegative results, thus we may have lost positive samples. Nevertheless, this assay was very useful for determining the presence of $\mathrm{HEV}$ in water samples, as shown in previous studies. ${ }^{10,25}$

Phylogenetic analyses showed that Salta HEV sequences belong to genotype 3. A newly proposed classification of HEV-3 subtypes suggests the presence of two clades within this genotype: 3 abchij and 3 efg. ${ }^{5}$ The samples in the present study were all found to belong to the first clade, which is consistent with all Argentinean sequences previously detected. ${ }^{10,15,16}$ Moreover, these strains belonged to the same clade as environmental samples from Córdoba, indicating that HEV strains that circulate in Salta are the same as in other parts of the Argentina (at least in the environment). Additionally, this group of sequences clustered near and intermingled with HEV sequences from swine in other countries, such as Bolivia and Brazil (bordering countries), which corroborates that pigs and/or other animals are possible sources of contamination of water sources. More studies focused on HEV detection in animals could elucidate this hypothesis.

Although the number of human samples analysed was relatively small, IgG anti-HEV antibody detection support the environmental findings and provide evidence of human HEV infection. The prevalence obtained (9\%) was similar to that found in Buenos Aires (9.5\%) ${ }^{16}$ and higher than that found in Córdoba $(4.4 \% ; p=0.035)^{10}$ in the same populations (people who attended health care centres for routine control) and using the same assay kit. Differences in HEV prevalence throughout the country may be partially explained by varying sanitary conditions, more frequent recreational use of rivers or differences in sample sizes analysed (the number in Córdoba was higher). Furthermore, in Salta and Buenos Aires, where the prevalence rates are higher, acute cases of hepatitis $E$ have been described, ${ }^{15}$ whereas none have been recorded in Córdoba. A limitation of this study is that serum and environmental samples were collected in different years; however, this difference is only about 1-7 y. Furthermore, the main goal of this investigation was to find HEV in environmental matrices as well as immunological evidence of HEV infection in humans, as specific IgG antibodies correspond to past HEV infections.

$\mathrm{HEV}$ positivity increased with increasing age, in accordance with previous studies in Argentina $^{10}$ and other countries, ${ }^{26,27}$ although this result did not reach statistical significance. This trend suggests that the risk of having been exposed to the virus, and ensuing seroconversion, increases with age.

The detection of IgM anti-HEV antibodies indicates a recent infection. Unfortunately, detection of HEV RNA could not be performed because samples were stored at $-20^{\circ} \mathrm{C}$, a temperature that is not optimal for conserving the RNA. As we do not have clinical data for these patients, it is not possible to determine the presence of symptomatic cases. However, despite the results of this study, acute hepatitis $E$ is not frequently diagnosed in Salta. This may be explained by a high rate of asymptomatic cases or the underdiagnosis of HEV infection, since testing for HEV may not be a standard practice in patients with unexplained acute or chronic liver disease. In this sense, it is necessary that physicians learn about the circulation of autochthonous HEV in Salta so that they can appropriately measure and manage the burden of HEV in this region.

Our study describes the circulation of HEV in the environment and in humans in a region not investigated until now, adding epidemiological evidence of the circulation of this virus in Argentina. This study provides further evidence for the need to incorporate the detection of HEV in the diagnostic algorithm of hepatitis in Argentina.

Authors' contributions: MBP and VER conceived the study. RP, HAC and VBR obtained and concentrated the environmental samples. VR selected the serum samples. MBP and BCL performed molecular detections and phylogenetic analyses. MGMW and VR performed serological assays. MBP, BCL and MGMW performed the statistical analyses. VER supervised all the work. MBP and VER drafted and wrote the manuscript. All authors read and approved the final manuscript. MBP and VER are guarantors of the paper.

Acknowledgements: We thank Dr Agustín Quaglia for his assistance on statistical analysis, James Leathers and LACE Laboratories for the use of the assay equipment.

Funding: This work was supported by the Agencia Nacional de Promoción de Ciencia y Técnica (PICT-Bicentenario 2010-0236) and Foundation Florencio Fiorini.

\section{Competing interests: None declared.}

Ethical approval: This study was carried out in accordance with the requirements of the Ministry of Health of Salta Province and complied with the ethical standards of the Helsinki Declaration (1964, amended most recently in 2008) of the World Medical Association. 


\section{References}

1 Khudyakov Y, Kamili S. Serological diagnostics of hepatitis E virus infection. Virus Res 2011;161(1):84-92.

2 Khuroo MS. Discovery of hepatitis E: the epidemic non-A, non-B hepatitis 30 years down the memory lane. Virus Res 2011;161(1):3-14.

3 Meng XJ. From barnyard to food table: the omnipresence of hepatitis $E$ virus and risk for zoonotic infection and food safety. Virus Res 2011;161(1):23-30.

4 Smith DB, Paddy JO, Simmonds P. The use of human sewage screening for community surveillance of hepatitis $E$ virus in the UK. J Med Virol 2016;88(5):915-8.

5 Smith DB, Simmonds P, Izopet J, et al. Proposed reference sequences for hepatitis E virus subtypes. J Gen Virol 2016;97(3):537-42.

6 Hoofnagle JH, Nelson KE, Purcell RH. Hepatitis E. N Engl J Med 2012; 367:1237-44.

7 Mirazo S, Ramos N, Mainardi V, et al. Transmission, diagnosis, and management of hepatitis E: an update. Hepat Med 2014;6:45-59.

8 Dos Santos DR, de Paula VS, de Oliveira JM, et al. Hepatitis E virus in swine and effluent samples from slaughterhouses in Brazil. Vet Microbiol 2011;149(1-2):236-41.

9 Idolo A, Serio F, Lugoli F, et al. Identification of HEV in symptom-free migrants and environmental samples in Italy. J Viral Hepat 2013;20 (6):438-43.

10 Martínez Wassaf MG, Pisano MB, Barril PA, et al. First detection of hepatitis $E$ virus in central Argentina: environmental and serological survey. J Clin Virol 2014;61(3):334-9.

11 Chen YJ, Cao NX, Xie RH, et al. Epidemiological investigation of a tap water-mediated hepatitis E virus genotype 4 outbreak in Zhejiang Province, China. Epidemiol Infect 2016;144(16):3387-99.

12 Van Tong H, Hoan NX, Wang B, et al. Hepatitis E virus mutations: functional and clinical relevance. EBioMedicine 2016;11:31-42.

13 Heldt FH, Staggmeier R, Gularte JS, et al. Hepatitis E virus in surface water, sediments, and pork products marketed in southern Brazil. Food Environ Virol 2016;8(3):200-5.

14 Baez PA, Lopez MC, Duque-Jaramillo A, et al. First evidence of hepatitis E virus in environmental waters in Colombia. PLoS One 2017;12 (5): 00177525.

15 Munné MS, Altabert NR, Vladimirsky SN, et al. Identifications of poyphyletic variants in acute hepatitis suggest an underdiagnosed circulation of hepatitis E virus in Argentina. J Clin Virol 2011;52(2): 138-41.

16 Munné MS, Altabert NR, Otegui LO, et al. Updating the knowledge of hepatitis $\mathrm{E}$ : new variants and higher prevalence anti-HEV in Argentina. Ann Hepatol 2014;13(5):496-502.

17 Poma HR, Gutierrez Cacciabue D, Garcé B, et al. Towards a rational strategy for monitoring of microbiological quality of ambient waters. Sci Total Environ 2012;433:98-109.

18 Poma HR, Rajal VB, Blanco Fernandez MD, et al. Evaluation of concentration efficiency of the Pseudomonas aeruginosa phage PP7 in various water matrixes by different methods. Environ Monit Assess 2013;185(3):2565-76.

19 Huang FF, Haqshenas G, Guenette DK, et al. Detection by reverse transcription-PCR and genetic characterization of field isolates of swine hepatitis $E$ virus from pigs in different geographic regions of the United States. J Clin Microbiol 2002;40(4):1326-32.

20 Tamura K, Stecher G, Peterson D, et al. MEGA 6: Molecular Evolutionary Genetics Analysis version 6.0. Mol Biol Evol 2013;30(12): 2725-9.

21 Di Rienzo JA, Casanoves F, Balzarini MG, et al. InfoStat 2016. Grupo InfoStat, FCA, Universidad Nacional de Córdoba, Argentina. 2016. http://www.infostat.com.ar.

22 Servicio Meteorológico Nacional de Argentina. Caracterización: estadísticas de largo plazo. https://www.smn.gob.ar/caracterizaci\% C3\%B3n-estad\%C3\%ADsticas-de-largo-plazo [accessed 7 February 2018].

23 Arends JE, Ghisetti V, Irving W, et al. Hepatitis E: an emerging infection in high income countries. J Clin Virol 2014;59(2):81-8.

24 Iaconelli M, Purpari G, Della Libera S, et al. Hepatitis A and E viruses in wastewaters, in river waters and in bivalve molluscs in Italy. Food Environ Virol 2015;7(4):316-24.

25 Masachessi G, Pisano MB, Prez VE, et al. Enteric viruses in surface waters from Argentina: molecular and viable-virus detection. Appl Environ Microbiol 2018;84(5):e02327-17.

26 Carrilho FJ, Mendes Clemente C, da Silva LC. Epidemiology of hepatitis $A$ and $E$ virus infection in Brazil. Gastroenterol Hepatol 2005; 28(3):118-25.

27 Montalvo Villalba MC, Guan M, Pérez A, et al. Seroprevalence of antibodies to hepatitis $\mathrm{E}$ virus in two large communities in Havana, Cuba. Trans R Soc Trop Med Hyg 2010;104(12):772-6. 